\title{
Mediatización de
}

\section{la religión: la relación} entre lo "religioso" ylo mediático en tiempos de red

\author{
POR MOISÉS SBARDELOTTO \\ m.sbar@yahoo.com.br Universidade do Vale do Rio dos Sinos (Unisinos), Brasil.
}

\section{RESUMEN}

Este artículo busca comprender los procesos comunicacionales en red que constituyen las religiones y las religiosidades contemporáneas. Para esto, primeramente, se profundiza la conceptualización en torno a la mediatización y mediatización digital, a partir de las relaciones entre sociedades, tecnologías y sentidos. Luego, a partir del contexto de las nuevas acciones y prácticas comunicacionales en red, se reflexiona sobre la relación entre el ambiente digital y el fenómeno religioso, apuntando a la especificidad digital dela mediatización dela religión contemporánea. Como caso de análisis, se examina la página Diversidade Católica en Facebook, porque apunta a procesos de transformación del catolicismo en su especificidad, en el contexto cultural contemporáneo. Como conclusión, se afirma que es posible percibir que la mediatización en su dimensión digital pluraliza la propia noción de religión y religiosidad. En redes comunicacionales online, el fenómeno religioso se manifiesta no solamente mediante acciones de religación (religare) entre lo humano y lo divino, sino principalmente de reconexión entre lo humano, lo social, lo tecnológico, lo simbólico y lo sagrado.

PALABRAS CLAVE: mediatización, mediatización de la religión, redes comunicacionales online, internet, religión. 


\begin{abstract}
This paper seeks to comprehend the communicational processes that constitute contemporary religions and religiosities. For this, firstly, it deepens the conceptualization around mediatization and digital mediatization, from the relations among societies, technologies and meanings. Then, from the context of the new communicational actions and practices, it reflects on the relationship between the digital environment and the religious phenomenon, pointing to the digital specificity of the mediatization of contemporary religion. As an analysis case, it examines the page Diversidade Católica on Facebook, for it points to processes of transformation of Catholicism, in its specificities, in the contemporary cultural melting pot. In conclusion, it states that it is possible to see that mediatization, in its digital dimension, pluralizes the very notion of religion and religiosity. In online communicational networks, the religious phenomenon manifests itself not only through actions of religation (religare) between the human and the divine, but mainly of reconnection among the human, the social, the technological, the symbolic, and the sacred.
\end{abstract}

KEYWORDS: mediatization, mediatization of religion, online communicational networks, internet, religion.

\title{
INTRODUCCIÓN
}

Analizar la mediatización de la religión es analizar los cambios vividos por la sociedad y por la religión en la contemporaneidad, complejizados por el fenómeno mediático, que posibilita nuevos procesos comunicacionales entre individuos, instituciones y los diversos campos sociales, a partir de lógicas y dinámicas emergentes. Mediante la comunicación de lo "religioso", la sociedad contemporánea percibe y expresa las religiones y las religiosidades por medio de prácticas de construcción de sentido que no están dadas de antemano, ni son neutras o automáticas.

Lo que vemos hoy es la inserción de las más diversas instituciones religiosas y sujetos religiosos en la trama de una sociedad en mediatización y, a su vez, la evolución de las religiones en general a través de acciones comunicacionales sobre lo "religioso". Especialmente en el ambiente digital, las prácticas sociales, a partir de lógicas mediáticas, complejizan el fenómeno religioso. Se forman nuevas modalidades de percepción y de expresión de lo sagrado en nuevos ambientes sociales. Cada vez más, el fenómeno religioso se traslada a ambientes públicos como las plataformas socio-digitales (Facebook, Twitter, Instagram, etc.).

Esto se ve con más claridad, por ejemplo, en el caso católico. Los siglos más recientes fueron marcados por innumerables marcos comunicacionales de la Iglesia Católica, como la primera imagen de un papa, León XIII, registrada en una película, en 1896; la primera transmisión de la voz papal en la radio, en 1931, cuando fue fundada la Radio Vaticana por Pío XI; y también la prime- 
ra transmisión de imágenes papales en la televisión, en 1949, de Pío XII. Sin embargo, todavía más recientemente, hubo una verdadera "digitalización del catolicismo", desde el primer email enviado por un Papa, Juan Pablo II, en un mensaje transmitido vía Internet a los obispos de Oceanía, en 1995, pasando por la histórica entrada del Papa Benedicto XVI en Twitter en 2012 (Sbardelotto, 2013); y también con el ingreso del Papa Francisco en Instagram con una cuenta personal en 2016 (Sbardelotto, 2016a).

Sin embargo, más allá de estos "usos sagrados" de los medios de comunicación por parte de la Iglesia Católica, el flujo de sentidos en Internet sobre lo que es "ser católico", sus saberes y haceres, encuentra brechas y escapes en el proceso de circulación social, yendo mucho más allá (o quedándose mucho más acá) de los intereses eclesiales institucionales, mediante acciones comunicacionales diversas por parte dela sociedad como un todo, que desvía y traslada los sentidos propuestos. Actualmente, al mismo tiempo en que los "grandes medios" van perdiendo el monopolio de la negociación de los sentidos sociales en general, las religiones pasan por un proceso semejante en relación a los sentidos religiosos de sus doctrinas y tradiciones. En los más diversos ambientes digitales, religiones y sociedad, en general, se encuentran ahora marcados por nuevas posibilidades de construcción de sentido, en términos de acceso, creación, almacenamiento, gestión, distribución y consumo de informaciones -yendo mucho más allá de las acciones tradicionales de los "grandes medios", entendidos como las corporaciones mediáticas, y mucho más allá de las acciones tradicionales de las instituciones religiosas volcadas a la comunicación-.

Esto ocurre gracias al surgimiento de nuevos agentes mediáticos -individuos, grupos y demás instituciones- que pasan a promover modalidades complejizadas de significación del socius y de lo sacrus en red, de forma pública, heterogénea y conectiva. En sociedades cada vez más mediatizadas es posible percibir que el flujo comunicacional de los sentidos, principalmente en red, no se deja detener o delimitar por cualquier estructura. O sea, lo "sagrado" pasa a circular, fluir, trasladarse en los meandros de Internet por medio de una acción no solamente del ámbito de la "producción" eclesial ni solamente industrial-mediática, sino también mediante una acción comunicacional de los innumerables inter-agentes conectados.

En los más diversos ámbitos de Internet, por lo tanto, instituciones religiosas y de la sociedad en general hablan sobre lo "religioso", re-significando la experiencia, la identidad, lo imaginario, las creencias, las prácticas, la doctrina, la tradición religiosa, actualizándolos para nuevos inter-agentes sociales y a públicos aún mayores, en una trama compleja de sentidos. En este proceso, vemos que la sociedad en general dice "esto es religioso", "esto no lo es". La sociedad hace algo con las religiones y religiosidades, en sus procesos de comunicación en red, por sobre la oferta religiosa disponible en Internet por parte de las instituciones religiosas o de los grandes medios. Construcciones 
sociales sobre lo "religioso" son ofrecidas no por un polo fijo de producción, sino ofrecidas-recibidas constantemente por los más diversos inter-agentes sociales (religiosos o no), más allá del control simbólico y teológico de las instituciones religiosas.

A partir de ese contexto, este artículo -síntesis de las principales conclusiones de nuestra investigación reciente sobre cómo se organizan los procesos mediáticos de circulación de lo "católico" en redes comunicacionales online ${ }^{1}$, que emergen en plataforma socio-digitales como Facebook y Twitter (Sbardelotto, 2016b)- busca comprender los procesos comunicacionales que constituyen las religiones y las religiosidades contemporáneas. Para esto, primeramente, profundizamos la conceptualización en torno a la mediatización y mediatización digital, a partir de las relaciones entre sociedades, tecnologías y sentidos.

Luego, a partir del contexto delas nuevas acciones y prácticas comunicacionales en red, reflexionamos sobre la relación entre el ambiente digital y el fenómeno religioso, rescatandola "mediunidad" mediático-religiosa y apuntandoa la especificidad digital dela mediatización dela religión contemporánea. Como caso de análisis, se examina la página Diversidade Católica en Facebook, por apuntar a procesos de transformación del catolicismo, en su especificidad, en el contexto cultural contemporáneo. El análisis es parte de un estudio de casos múltiples, articulado con entrevistas focales semiestructuradas con los principales responsables de los casos en análisis, en Brasil y en el Vaticano.

Como conclusión veremos que más allá de las especificidades de cada tradición religiosa, podemos percibir que la mediatización en su dimensión digital pluraliza la propia noción de religión y religiosidad. En redes comunicacionales online, el fenómeno religioso se manifiesta no solamente mediante acciones de religación (religare) entrelo humanoylo divino, sino principalmente de reconexión entrelo humano, lo social, lo tecnológico, lo simbólico, lo sagrado.

\section{MEDIATIZACIÓN: PROBLEMATIZACIONES SOBRE LA RELACIÓN ENTRE SOCIEDADES, TECNOLOGÍASY SENTIDOS}

Vivimos actualmente en una sociedad marcada por una "nueva ambiencia" socio-comunicacional (Gomes, 2008). En el contexto contemporáneo, son innumerables los agentes sociales conectados que manifiestan comunicacionalmente sus competencias sobre diversos ámbitos de lo social, inclusive lo religioso, más allá de la acción de las corporaciones mediático-industriales. Se trata de un "viraje mediático", marcado por un "grado históricamente único" de integración de lo tecnológico y de lo sociocultural” (Friesen \& Hug, 2009, p. 65; trad. nuestra). En este proceso, las condiciones de posibilidad de interacción humana, de comunicación social y de organización social pasan a ser condicio-

1 El concepto refiere a las diversas matrices de comunicabilidad en interconexiones socio-digitales, involucrando procesos comunicacionales transversales que se establecen a partir de conexiones digitales, en las plataformas digitales y más allá de ellas. 
nadas (no necesariamente determinadas) por lógicas y dinámicas mediáticas. Y eso también afecta las prácticas sociales de instituciones religiosas y de la sociedad como un todo en su relación con lo "religioso".

Sin embargo, es preciso tomar en consideración las expresiones comunicacionales de las religiones a lo largo de la historia, pues los procesos de comunicación y las tecnologías mediáticas de cada época condicionaron cómo las religiones se desarrollaron históricamente. Sin embargo, la mayoría de los estudios de la interfaz medios/religión no toman en cuenta esta dimensión socio-histórica, sin relacionar lo que sucede ahora con lo que ya sucedió antes. "Como resultado, gran parte del pensamiento sobre media y religión ve lo que sucede hoy como una cuestión distintivamente moderna" (Horsfield, 2015, p. 2; trad. y cursivas nuestras).

Basta acompañar la historia del cristianismo primitivo, por ejemplo, para percibir ya entonces diversos procesos comunicacionales que moldearon su evolución a lo largo de la historia y de las culturas (testimonios, textos, cartas, libros, rituales, imágenes etcétera), lo que apunta a una cierta continuidad de los procesos actuales en relación al pasado, pero, al mismo tiempo, a una gran capacidad de reinvención y reconstrucción. Y lo quevemos hoy son desarrollos de esa génesis comunicacional del cristianismo, que está relacionada con los grandes cambios y transformaciones delos procesos comunicacionales alolargo de la historia; que apuntan, a su vez, a aquello que llamamos mediatización.

La mediatización "se estructura como un proceso social más complejo que trae en su estela los mecanismos de producción de sentido social" (Gomes, 2013, p. 136; trad. nuestra), y que corre a través de varios momentos de la historia y varias expresiones culturales. Lo que tenemos hoy es una mayor evidencia de tales procesos, gracias a la complejización de sus manifestaciones que tornan a la mediatización más observable empíricamente en las prácticas sociales. Por eso, retomar esa larga trayectoria y esa "perspectiva de largo plazo" de la mediatización, como nos sugiere Verón (2014), nos permite evitar pensarla como un proceso inexistente en épocas anteriores o como una mutación y una ruptura casi a-históricas en los procesos sociales. Al contrario, es preciso asumir una perspectiva social e histórica, que dé énfasis a las complementaciones y mestizajes, y no a las rupturas y mutaciones radicales.

Entendiendo a la mediatización como un proceso socio-comunicacional históricamente emergente, es preciso destacar que, desde el punto de vista observacional, sin embargo, es la experiencia social contemporáneala que posibilita el surgimiento de lo que llamamos mediatización como objeto de reflexión comunicacional. Eso ocurre gracias a puntos de saturación y bifurcaciones en la escala espacio-temporal, en términos de velocidad y alcance de los procesos comunicacionales, dondela curva histórica de su evolución sufre movimientos significativos. Así, al mismo tiempo que es posible percibir una continuidad de los procesos comunicacionales, que vienen desde el proceso ancestral de pintar 
las cavernas, también es preciso reconocer su transformación y cambio a partir del siglo XX, en aceleración cada vez mayor a causa de los avances tecnológicos y de la industrialización reciente. No se trata de un mero desarrollo gradual y lineal, sino de una evolución en procesos de cambio históricos heterogéneos e irreversibles, no tanto mediante una "selección natural", sino por medio de una selección humana, tecnológica, simbólica, cultural, social.

En general, sin embargo, en los estudios de comunicación, el sentido de los media -y, consecuentemente, de mediatización- quedó vinculado a la observación de la acción de los grandes medios de comunicación de masa o a las corporaciones mediáticas que organizarían y darían sentido al socius, como un campo social autónomo y central, el "campo de los medios", en aquello que se convino en llamar "sociedad de los medios". Los media, así, eran entendidos meramente como tecnologías de la información, o como instituciones mediáticas corporativo-empresariales, o aún como elementos extra-sociales.

Hoy está ocurriendo una transformación profunda que cuestiona la "ontología" en la cual se basaba el paradigma de la comunicación de masa. "Los productores y consumidores de los medios ahora son, muchas veces, la misma persona; las producciones culturales profesional y amateur no están distantes, pero sí, superponiéndose íntimamente, como áreas del mismo vasto espectro" (Couldry, 2010, p. 52; trad. nuestra). Actualmente, tendríamos un salto o hasta una ruptura social con modelos previos, a partir de nuevas prácticas comunicacionales, comola circulación delo "religioso" en red, que demandan la revisión, por un lado, de la idea de que el "profesionalismo" está solo en el ámbito de las corporaciones mediáticas empresariales, y, por otro lado, de que las prácticas sociales se resumen a acciones de "audiencias", "usuarios" o "consumo".

En la actualidad, cada vez más, "pasamos de la era de los medios de masa a la era de la masa de medios", donde se explicita la "posibilidad de cualquier persona de transformarse en medio de comunicación, capaz de hablar para millones de otras personas (Alves, 2013, p. 3; trad. nuestra). La mediatización digital apunta justamente a una travesía a partir del "desierto, con sus cactus, arbustos secos y pocos animales" (como metáfora del ambiente mediático de la era industrial) rumbo a una "floresta amazónica comola metáfora para explicar lo que se está formando después del diluvio digital: una selva húmeda, llena de agua, solyvida, con una enorme biodiversidad, donde cualquier ser minúsculo tiene una chance de sobrevivir" (Ibídem: p. 9; trad. nuestra) (como metáfora del actual contexto comunicacional).

Esto presupone un ecosistema mediático mucho más complejo, que demanda abordajes teóricos atentos al surgimiento de los fenómenos y a los cambios y transformaciones de las prácticas comunicacionales mediante procesos mediáticos. Pues, con el avance tecnológico y su apropiación social en procesos comunicacionales emergentes -como la circulación de lo "religioso" en red-se va constatando cada vez más "una aceleración y diversificación de los modos 
por los cuales la sociedad interactúa con la sociedad" (Braga, 2012, p. 35: trad. nuestra). En este contexto, es preciso profundizar algunos aspectos centrales que, desde nuestro punto de vista, tiñen la noción de mediatización.

\section{DE LOS MEDIA, A LA AMBIENCIA, A LA MEDIATIZACIÓN}

Allidiar con las cuestiones mediáticas, el campo religioso recurre a diversas metáforas. En el caso católico, los documentos papales están repletos de tales metáforas comunicacionales, que remiten a la transformación desencadenada por la mediatización contemporánea. El Papa Benedicto XVI, por ejemplo, solicitaba que la Iglesia Católica ejerciera la "tarea de evangelizar este continente digital" (2009, párr. 10; cursivas nuestras). Por otrolado, reconocía el desarrollo delasllamadas "redes sociales", que "están contribuyendo a que surja una nueva "ágora', una plaza pública y abierta” (Ibídem, 2013, párr. 1, cursivas nuestras).

La referencia a esta "espacialidad" presente en los discursos papales es un síntoma de la mediatización contemporánea. Despunta ahí la comprensión de los media como "punto de partida para la constitución de un nuevo bios con un tipo nuevo de sociabilidad. El media es, así, al mismo tiempo, ambiente y recurso, o sea, elementos adaptativos de una filogénesis histórico-cultural" (Sodré, 2014, p. 246; trad. nuestra). Esto también hace que se reorienten los modos de pensar y de sentir, formando otro tipo de polis, o, en este caso, otro tipo de ekklesia (asamblea) religiosa.

La mediatización, por consiguiente, se convierte en la "clave hermenéutica para la comprensión e interpretación de la realidad" (Gomes, 2008, p. 30; trad. nuestra), por revelar la naturaleza comunicativa y comunicacional delas culturas y las sociedades. Y el "contenido" del fenómeno de la mediatización son los procesos mediáticos, cada vez más amplios, cada vez más acelerados, cada vez más diversificados (Gomes, 2010). Pero no se trata sólo de la institucionalización de un campo social mediático, como decíamos, sino de un meta-proceso comunicacional (Krotz, 2007) -con especificidades propias en cada fase histórica- de construcción simbólica de la vida cotidiana y del ambiente cultural de las sociedades. La mediatización, por lo tanto, se sitúa en una "dialéctica de las reciprocidades en el cambio de la comunicación mediática, por un lado, yel continuo cambio social y cultural, por otro" (Hepp, 2012, p. 44; trad. nuestra).

En este sentido, la mediatización es meta-mediática (Gomes, 2013), pues es la génesis de medios sociales (sociedades y culturas) que generan y son generados por medios mediáticos (los media) en complejidad creciente. Emerge, de esta forma, una nueva naturaleza organizacional de la sociedad, mediante la "constitución de una ambiencia más amplia que la mera focalización en los dispositivos tecnológicos de comunicación”, o sea, un "bios mediático (...) que se forma con la sociedad de la información actual” (Gomes, 2015, p. 48; trad. y cursivas nuestras). 
La mediatización digital de la religión se explicita, empíricamente, mediante prácticas comunicacionales en torno a la circulación de lo "religioso", que van más allá de las fronteras espaciales; tales prácticas, a su vez, realimentan el "caldo" histórico de la mediatización, que se desarrolla en el eje del tiempo, dinamizando las transformaciones evolutivas (en sentido de gradualidad, no necesariamente de mejoría o perfeccionamiento) de las religiones, religiosidades y instituciones religiosas, en sus diversas mediaciones comunicacionales.

La mediatización, por lo tanto, es tanto un fenómeno procesual, cuanto un proceso fenoménico. O sea, al mismo tiempo que construye la mediatización como proceso, la sociedad (y sus prácticas localizadas) es construida por ella y no la controla como fenómeno, dada la complejidad de los contextos culturales específicos: interaccionales, híbridos, intersubjetivos, indeterminados, irreversibles, mutables, complejos. De este modo, la mediatización no se manifiesta solamente como "un orden de mediaciones socialmente realizadas en el sentido de la comunicación” (Sodré, 2012, p. 21; trad. nuestra), sino también y sobre todo comola "principal mediación de todoslos procesos sociales" (Braga,2012, p. 51; trad. nuestra).

A partir de este panorama, podemos ahora articular el concepto de mediatización, ya complejizado, con una reflexión sobre las prácticas religiosas contemporáneas en redes comunicacionales online.

\section{MEDIATIZACIÓN DIGITAL DE LA RELIGIÓN: PROBLEMATIZACIONES SOBRE LA RELACIÓN ENTRE EL AMBIENTE DIGITAL Y EL FENÓMENO RELIGIOSO}

A partir de la "revolución comunicacional" debida en gran parte a las innovaciones socio-tecnológicas digitales, especialmente con Internet, surge también la necesidad de una re-problematización de la propia noción de religión y de su relación con los procesos mediáticos, porque:

La mediatización de la religión se traduce no solamente como un momento de alteración de las prácticas de las instituciones religiosas, sino también como una aparente reestructuración, más amplia, de los significados de qué es "sagrado", "religioso" y de la "experiencia religiosa" (Martino, 2012, p. 237; trad. nuestra).

Así, la interfaz media/religión necesita ser repensada, para que la comprensión de aquello que pasó a ser definido corrientemente como "mediatización de la religión" -involucrando la presencia de la religión en los medios y de los medios en las prácticas religiosas- no comprenda sesgos o preconceptos exclusivamente optimistas o pesimistas acerca del fenómeno mediático contemporáneo en su relación con las diversas expresiones religiosas. 


\section{MEDIATIZACIÓN DE LA RELIGIÓN: REVISIÓN CRÍTICA}

Gran parte de los estudios sobre el concepto de "mediatización de la religión", en general, tratan de un análisis de la centralidad de los medios, de las instituciones mediáticas o de las tecnologías mediáticas en las prácticas de sentido en torno a las creencias y prácticas religiosas. No negamos que tales observaciones tengan su relevancia para la comprensión del fenómeno. Sin embargo, creemos que, en dichos estudios, elénfasis recae, en gran parte, en apenas una parte del proceso, en uno de sus polos, sin considerar su complejidad.

Dichas formas de analizar el fenómeno parten, principalmente, de dos perspectivas de reflexión centrales y articuladas: la dependencia/subordinación de la religión ante los medios, y viceversa; y la influencia/prepotencia de los medios sobre la religión, y viceversa. Repasaremos aquí, de modo crítico, algunos de los estudios más recientes que abordan específicamente el concepto de "mediatización de la religión" en sus análisis y reflexiones.

En relación a la perspectiva de análisis de la dependencia/subordinación de la religión en relación a los medios, y viceversa, Hjarvard (2013) defiende quela mediatización de la religión se manifiesta cuando "los imaginarios y las prácticas religiosas se tornan crecientemente dependientes delos media" (2013,p.80; trad. y cursivas nuestras). Según esta perspectiva, la religión se mediatiza cuando "aparece" en los medios de comunicación, mediante la creciente presencia de temáticas religiosas en los media. Según estos estudios, las religiones, para tener sentido en la sociedad contemporánea, marcada por procesos comunicacionales mediáticos, dependería de los media para su existencia.

Otros análisis entienden la mediatización de la religión como la manipulación de los medios (considerados casi como tecnologías neutras) por parte de las religiones. Se constata que, "para que el individuo esté cada vez más conectado a lo sagrado, la Iglesia busca llegar a cada vez más fieles, sirviéndose de diversos medios -como los digitales-para alcanzar su fin principal" (Sousa, 2011, p. 27; trad. y cursivas nuestras).

Ya la perspectiva de análisis en términos de influencia/prepotencia mediática sobre la religión, o religiosa sobre los media, está relacionada a la constatación de la "adecuación institucional (religiosa) a las lógicas de producción mediática, sea de los fieles y de sus prácticas, al ambiente mediático" (Martino, 2015, p. 12; trad. nuestra). Así, el análisis defiende que la religión no podría ni siquiera "escapar de la dinámica convergente de la mediatización que constituye la cultura actual, razón por la cual “las estructuras religiosas (...) seguirán sufriendo indefinidamente el impacto de los fuertes vendavales de la mediatización" (Gutiérrez, 2010, pp. 189-193; trad. y cursivas nuestras).

Por otro lado, esta perspectiva asume los procesos mediáticos en relación a la influencia/prepotencia de la religión sobre los media, evidenciando un "carácter religioso a esa conexión entre real-virtual, tecnología, misterio y es- 
pectralidad", en que la "metáfora de "cristificación" de los medios" toma fuerza $y$, aun siendo asumidamente "exagerada", es una tesis que "valdría la pena seguir" (Burity, 2003, pp. 84-87; trad. nuestra). En suma, según esta perspectiva, cuando "la religión se mediatiza, la técnica es sacralizada" (Miklos, 2012, p. 191; trad. nuestra).

Como vemos, estas perspectivas son desencadenadas por lógicas de análisis que restringen el estudio de la mediatización de la religión a un encuadre que no tiene en cuenta un fenómeno mucho más complejo y que se manifiesta en la articulación con otros fenómenos sociales. Por un lado, las religiones son vistas como "rehenes" de los procesos mediáticos, en que los media serían apenas "herramientas" a disposición de las religiones. $\mathrm{O}$, entonces, solamente la religión ylos medios institucionalizados harían parte del espectro de análisis, razón por la cual la mediatización de la religión llevaría a la transformación de las creencias y prácticas religiosas en mera "mercadería" simbólica y material.

Es necesario deconstruir esas perspectivas y lógicas, pues, aunque pongan de manifiesto la relevancia de los procesos mediáticos y religiosos, nos parecen poco profundas para describir el fenómeno de la mediatización de la religión, restringiéndose a los "efectos" de los medios sobre la religión, a los "usos" religiosos de los media, o a ambos como modos trans-históricos, inmutables, independientes y autónomos de construcción de sentido (Hoover, 2006). Lo que está en juego, al revés, es la relación de las propias religiones y religiosidades con la comunicación que, en general, no es problematizada, sino vista como una solución frente a los desafíos culturales contemporáneos.

Por eso, es preciso dar un salto cualitativo en los análisis, yendo más allá de la simple reflexión sobre los "efectos/impactos mediáticos" sobre la religión, o sobre los "usos religiosos" de los medios de comunicación. Se percibe hoy una "ideología" tecnocomunicacional que a veces atraviesa a las instituciones religiosas, especialmente al dar un énfasis excesivo al papel de las tecnologías comunicacionales, como meros medios a disposición de los propósitos institucionales de las religiones, por posibilitar la transmisión de forma "eficiente, eficaz y amplia" de su mensaje religioso a la sociedad contemporánea. Al contrario, es preciso profundizar el análisis y percibir la complejidad de la integración, articulación, hibridación entre religión y media, procesos en que:

La exposición mediática sirve como una especie de acelerador para el discurso religioso, proveyendo el "oxígeno de la publicidad" para ideas y movimientos que no hayan sido capaces de alcanzar una preeminencia antes. La religión también actúa como una especie de acelerador para los medios, actuando como algo fuera del ámbito del discurso mediático normal que existe, interviene y contradice ese discurso (Hoover, 2006, p. 289; trad. nuestra).

Por eso es preciso estar atento a las micro-alteraciones en la vivencia religiosa, la llamada "mediamorfosis de la fe", "por medio de la cual (las religiones) 
evolucionan y se complejizan cada vez más en su relación con las prácticas y los procesos socio-mediáticos" (Sbardelotto, 2012, p. 150). El desafío de análisis del fenómeno de la mediatización de la religión está lanzado: contemplar los ambientes mediático-religiosos en la búsqueda de "acceder a una realidad que esconde un ambiente social más amplio", en que "el cuadro final no es la suma de los hechos individuales, sino una realidad metamorfoseada que, inclusive, ocasiona un nuevo modo de ser religioso" (Gomes, 2012, p. 18).

Frente a la complejidad de la mediatización de la religión en la era digital, también es preciso profundizar la reflexión sobre el fenómeno de la comunicación contemporánea en su relación con las prácticas religiosas subyacentes a este concepto.

\section{LA “MEDIUNIDAD” MEDIÁTICO-RELIGIOSA}

Modalidades más complejas de comunicación pueden generar y mediar modalidades más complejas de religión y religiosidad. En esta nueva complejidad social, las religiones y sus instituciones van siendo impulsadas a modificar sus propias estructuras comunicacionales y sistemas internos y externos de significación de lo sagrado, mediante no sólo procesos de adopción (adopt) o de adaptación (adapt) a los procesos mediáticos, sino también de apropiación, negociación, reconstrucción. En esto también se encuentra una más de las facetas de mediatización, pues, además de ser fuente de información, el medio comunicacional pasa también a generar, mediante procesos sociales, un ambiente social de experiencia y de práctica de la fe tecnológicamente mediadas.

Por eso, es preciso asumir con todas sus consecuencias la crítica a las miradas funcionalistas, instrumentales, institucionales o esencialistas que muchas veces tiñen los análisis de la relación media/religión. En relación al polo mediático, ya abordamos la cuestión más arriba. En relación al polo religioso, es preciso asumir la perspectiva de que no es "la religión" en alguna forma pura o esencialista lo que debe estar en cuestión, sino, al contrario, "la forma y el perfil de lo 'religioso' y su constitución” (Hoover, 2014, p. 198; trad. nuestra), en que la definición de lo "religioso" no es dada por la autoridad religiosa, sino que emerge a partir de las prácticas sociales en torno a lo sagrado.

De este modo, la distinción entre religión y media no puede asumir la connotación de una separación entre "sagrado" (la religión como algo puro, raro, trascendente) y "profano" (los media como algo duro, racional, desencantado). Esto significa que muchas "fronteras que pensábamos existían entre "lo religioso' y 'lo secular' se rompieron hace mucho tiempo y son crecientemente problemáticas" (Hoover, 2009, p. 135; trad. nuestra). La religión, hoy, se manifiesta cada vez más como "algo que ocurre mientras las personas trabajan con recursos simbólicos provistos por su cultura para crear sentido para sus vidas diarias, para compartir experiencias de temor y misterio" (Horsfield, 2015, p. 1; trad. y 
cursivas nuestras). Se trata, por lo tanto, de un proceso comunicacional, pues "la religión es (...) esencialmente una construcción comunicativa" (Knoblauch, 2014, p. 11; trad. nuestra).

De esta forma, entendidas las religiones como sistemas comunicacionales de relaciones simbólicas en torno a lo sagrado y los media como sistemas comunicacionales de relaciones entre medios en torno a prácticas socioculturales, la interfaz media/religión es un fenómeno cultural simbiótico, híbrido, complejo marcado por procesos significativamente comunicacionales. Por eso es preciso tener en cuenta aquello que las diversas prácticas religiosas realmente hacen comunicacionalmente, y cómo lo hacen. Pensar la mediatización de la religión no significa solamente percibir cómo las religiones hoy son "mediadas" por los medios contemporáneos. El proceso de mediatización de la religión es mucho más complejo que la mediación religiosa o mediática.

En sociedades en mediatización, en suma, las religiones no pueden más ser entendidas solamente como instituciones o doctrinas fijadas; también tienen que ver con prácticas y experiencias encarnadas socialmente por individuos, colectivos e instituciones en ambientes públicos de construcción de sentido sobre lo sagrado. Hoy, prácticamente todos los ámbitos de la vida religiosa-históricamente marcada por rituales iniciales, reservados a pocos escogidos-están expuestos a la experiencia de cualquier individuo. En estos desplazamientos, el fenómeno mediático amplíalos sentidos culturales delas religiones, ultrapasando el control de las instituciones religiosas, abriéndose a las múltiples construcciones de sentido social en procesos mediáticos, que, a su vez, no están dados de antemano, sino que se constituyen a partir de prácticas religiosas locales.

En este sentido, conceptos como medios religiosos, religión mediática y religión mediatizada no abarcan el fenómeno, que se expande más allá del polo empresarial mediático y más allá del polo religioso institucional, encontrando nuevas formas de complejización en el ambiente digital.

\section{LA ESPECIFICIDAD DIGITAL DE LA MEDIATIZACIÓN DE LA RELIGIÓN}

Especialmente con el proceso de digitalización, la "mediunidad" medial religión pasa a ser marcada principalmente por una ruptura de escala espaciotemporal y por una descontextualización y recombinación de sentidos. Así, si estamos viviendo una "revolución comunicacional" a partir de la digitalización, las creencias y prácticas religiosas, al empaparse de esta cultura, pasan a constituirse a partir de nuevos procesos que merecen reflexión y análisis.

La digitalización empuja a las religiones y sus instituciones a asumir nuevas formas de percepción del mundo en que habitan y nuevas formas de expresión de sus tradiciones y doctrinas dentro de este contexto. Ocurre un desplazamiento de las prácticas de fe para el ambiente online, a partir de lógicas mediáticas, complejizando el fenómeno religioso y los procesos comunicacionales mediante nuevas temporalidades, nuevas espacialidades, nuevas materialida- 
des, nuevas discursividades y nuevas ritualidades (Sbardelotto, 2012). Algunos elementos de continuidades, rupturas y transformaciones que apuntan a nuevas formas de ser religioso en Internet, de un modo general, ya fueron analizados por nosotros en otro contexto (Sbardelotto, 2012;2014), por eso nos restringiremos aquí a aspectos más directamente relacionados con las redes comunicacionales online.

Acompañando el proceso histórico de la religión como medium, Pace (2013) nos ayuda a comprender que una religión nace a partir de una "palabra viva”, manifestada como una revelación, una epifanía, una comunicación a un interlocutor original, a una autoridad (comunicación de primer nivel). Esta palabra viva se transforma en una "palabra dada", mediante la comunicación de la comunicación de este intérprete autorizado o de un texto sagrado, explicitando socialmente esta identidad religiosa (comunicación de según nivel). A su vez, esta palabra dada es conservada en la memoria y en la comunicación de una "comunidad de la palabra", cuya unidad es mantenida simbólicamente en sus teologías y liturgias, en lo que sería una comunicación de tercer nivel.

Hoy, según el autor, tendríamos una comunicación de cuarto orden, pues, con Internet y los medios digitales, es como si ese tercer nivel de comunicación reflexiva produjese un cuarto nivel que reconstruye comunicacional, social y públicamente la matriz original del mensaje religioso. $\mathrm{O}$ sea, en las redes comunicacionales online, la religión "se expone a la interacción con un ambiente mucho más vasto, complejo y diferenciado de aquellos con que habitualmente entra en contacto"(Pace, 2013,p.93; trad. nuestra). Retomandoa Verón(2012), por lo tanto, los elementos emergentes decisivos en la especificidad de la mediatización de la religión en ambientes digitales son el alcance y la velocidad de los procesos mediáticos a ellos relacionados.

La religiosidad online, en ese sentido, es tanto un producto como una señal de cambio producida por el fenómeno de la mediatización. En este proceso, la coexistencia de tantos puntos de vista diferentes sobrelo "religioso" permite que lapersona se sitúe en un ambiente teológicoy doctrinal másfluido, que posibilita la experimentación religiosa. Esto porque, en redes comunicacionales online:

\begin{abstract}
Los significados que los diversos componentes atribuyen a lo que los reúne (como las creencias y prácticas religiosas) son discutidos, sometidos a una continua negociación, aceptados y redefinidos, acogidos con entusiasmo o con críticas. Todo esto contribuye para formar significados inter-subjetivos que, por definición, no pueden exhibir un fundamento absoluto. Laparticipación de más personas en tal proceso de definición y redefinición de los significados dilata el sentido a ser atribuido a palabras-clave (por ejemplo: las palabras "Dios" o "espiritu") o a objetos que pretenden incorporar un mensaje simbólico" (Pace, 2013, p. 22; trad. y cursivas nuestras).
\end{abstract}

De este modo, es relevante observar lo que acontece cuando la experiencia y la comunicación religiosas se manifiestan en los ambientes digitales, que 
conceden un grado de autonomía y libertad mucho mayores a la construcción de sentido en una escala más amplia y abarcativa, liberando una autonomización comunicacional que puede poner en crisis los principios básicos sobre los cuales se fundamenta la fuerza comunicativa de las religiones históricas (Pace, 2013). El desafío, por lo tanto, es "religar", teóricamente, el enlace entre los procesos mediáticos digitales y las prácticas religiosas, buscando comprender los vínculos que unen, hoy, los universos simbólico-religiosos y los ambientes comunicacionales en proceso de cambio en el tiempo, en el espacio y en sus materialidades. Es lo que veremos, en síntesis, en el caso Diversidade Católica en Facebook.

\section{EL CASO DIVERSIDADE CATÓLICAEN FACEBOOK}

Más allá del refuerzo de la presencia institucional de las religiones en red, vemos que el sentido del "ser religioso" en la sociedad, mediante nuevas prácticas comunicacionales, va mucho más allá (o queda muy acá) de su posible "aceptación" por parte de las instituciones religiosas. Tomemos el caso católi$\mathrm{Co}^{2}$. Esto se da tanto en las respuestas/comentarios que quedan publicados en las propias páginas y cuentas oficiales de la Iglesia Católica en las plataformas socio-digitales, así como en las acciones comunicacionales de los inter-agentes en general, mediante tweets, compartidas y nuevos posteos sobre el catolicismo, y además en la creación de páginas y grupos públicos dedicados al catolicismo en esas plataformas, sin vinculación institucional, por parte de usuarios comunes, a partir de los más variados puntos de vista.

Entrevemos aquí una verdadera experimentación religiosa heterogénea y difusa en las plataformas socio-digitales por parte de diversos inter-agentes, en que las manifestaciones comunicacionales explicitan más fuertemente el aspecto público del fenómeno religioso, mediante prácticas interaccionales emergentes que producen alteraciones en el propio catolicismo. En todo este proceso identificamos algunaslógicasy dinámicas mediáticas, por medio delas cuales instituciones eindividuos religiosos son impelidos por la nueva complejidad social a modificar sus estructuras comunicacionales y sistemas internos y externos de significación de lo sagrado en la sociedad.

Más allá de los aspectos institucionales del catolicismo -que también va siendo resignificado y reconstruido en las interacciones con los diversos interagentes- la mediatización digital involucra aún un proceso de autonomización comunicacional. En el caso de la religión, esto lleva a nuevas configuraciones religiosas, en que sujetos comunes toman la palabra social y públicamente, dando nuevos sentidos a los sentidos religiosos en general.

2 El interés por el catolicismo se debe, primeramente, a la relevancia socio-histórico-cultural de la Iglesia Católica en Brasil. En términos cuantitativos, los datos oficiales más recientes apuntan una mayoría católica en la población brasileña (64,6\% según el Censo 2010). Entretanto, más allá de los datos estadísticos, lo más importante es la tradición y la presencia del catolicismo como referencia religiosa estructurante de la nacionalidad y de la cultura en Brasil. 
Esto es, Internet, por su facilidad de acceso y de uso, y por la expansión del alcance y de la amplitud de las interacciones sociales, da el poder de la "palabra pública" a aquellos que no tenían acceso a los aparatos mediáticos y eclesiales tradicionales.

Si el catolicismo, "con su estructura de carácter performativo, ya tiene un potencial de incorporar la diversidad" (Teixeira \& Menezes, 2009, p. 9), al posicionarse en una plaza pública como Internet y sus redes, la Iglesia se coloca en una encrucijada todavía más compleja de discursos otros, que no le pertenecen y se le escapan. Y a esta diversificada y difusa red de relaciones entre símbolos, creencias y prácticas vinculadas a la experiencia religiosa católica, a la tradición histórica del catolicismo o a la institución Iglesia Católica lo llamamos lo "católico". Como producto de la interacción y de la comunicación entre los inter-agentes sobre el catolicismo, es lo "católico" lo que posibilita este proceso de interacción y comunicación.

En ese contexto, nuestra investigación buscó comprender cómo se organizan los procesos mediáticos de circulación de lo "católico" en redes comunicacionales online que emergen en plataformas socio-digitales como Facebook y Twitter. Intentamos entender además cómo se constituyen las acciones comunicacionales de la institución Iglesia Católica y de la sociedad en general sobre el catolicismo, en el proceso de mediatización digital. También analizamos el modo por el cual se organizan los procesos mediáticos de circulación de lo "católico" en plataformas digitales como Twitter y Facebook y, de modo más amplio, buscamos inferir posibles transformaciones que ocurren en la reconstrucción de la experiencia católica, en términos de percepción y expresión de sus símbolos, creencias y prácticas. Metodológicamente, hicimos un estudio de casos múltiples, articulado con entrevistas focales semiestructuradas con los principales responsables de los casos en análisis, en Brasil y en el Vaticano.

Tales casos fueron seleccionados a partir dela observación de cuatro niveles diferentes de circulación de lo "católico" en red r $^{3}$. Acá, nos restringiremos a un nivel minoritario-periférico católico brasileño, en el que fue examinada la página Diversidade Católica en Facebook. Ésta sintetiza, de forma más específica, para los fines de este artículo, las principales transformaciones emergentes con la mediatización digital de la religión. Analicemos.

En las plataformas sociodigitales, se constata la existencia de innumerables casos de ambientes creados por personas comunes sobrelas temáticas católicas, o sea, presencias no oficiales, no institucionales, alternativas, sobrelo "católico". En ellas, a partir de su punto de vista sobre el universo católico, los internautas se apropian de elementos mediático-religiosos, reconstruyendo y resignifican-

3 Los demás casosanalizados fueron: en un nivel supra-institucional, analizamosla cuenta personal del Papa en Twitter en portugués, @Pontifex_pt; en un nivel institucional Vaticano, la página Rádio Vaticano - Programa Brasileiro en Facebook; en un nivel socio-institucional brasileño, la página del proyecto Jovens Conectados, de la Comisión Episcopal Pastoral de la Juventud de la Conferencia Nacional de los Obispos de Brasil (CNBB) en Facebook. 
do públicamente el sentido del catolicismo. Dada la actual coyuntura sociocultural y, principalmente, eclesial, se destacan los casos en que estas páginas explicitan públicamente los enfrentamientos en el interior del catolicismo. Una de las cuestiones más controvertidas del catolicismo contemporáneo es precisamente la cuestión gay y de la identidad de género Según Pondé (2011), la homoafectividad es no solamente una de las "mayores transformaciones sociales de las últimas décadas del siglo XX”, sino también, en ámbito eclesial, "uno de los temas más duros para el catolicismo en el inicio de este siglo" (2011, p. 75; trad. nuestra).

En el contexto eclesial brasileño, esta realidad también se torna cada vez más fuerte, aunque entre tensiones y desconfianzas. Una de las principales revistas de reflexión teológico-pastoral católica en Brasil, Vida Pastoral, trató la cuestión de la homoafectividad y la fe cristiana en su edición de diciembre de 2014, provocando un intenso debate. En la edición, el teólogo y padre jesuita Luis Correa Lima afirma: "Importante señal de los tiempos actuales es la visibilización de la población homosexual (...) Los gays son parte de la sociedad, $y$, al visibilizarse, aspiran a la ciudadanía plena, con los mismos derechos y deberes de los demás (Lima, 2014, pp. 29 y 30; trad. y cursivas nuestras).

Quedan evidentes, en esa reflexión, los límites, las necesidades y las posibilidades para trabajar esta cuestión en el ámbito católico. Se trata de una importante señal de los tiempos actuales, como afirma el autor, esto es, una realidad sociocultural emergente que provoca y convoca a la Iglesia a ver el hecho a partir de una perspectiva trascendente, a partir de su propia misión como comunidad eclesial cristiana. Esta "señal" necesita ser "visibilizada" en la cultura, en suma comunicada, con todo lo que eso implica.

Es en este contexto de afirmación y búsqueda de reconocimiento por parte de las personas gays católicas que se inserta la acción comunicacional de la página Diversidade Católica. El grupo nació en el 2006, en Río de Janeiro. Su presentación disponible en su página web lo define como "un grupo de laicos católicos que comprende que es posible vivir dos identidades aparentemente antagónicas: ser católico y ser gay, en una amplia acepción de este término, incluyendo toda la diversidad sexual (LGBT)"4. El grupo también reitera su fidelidad a la Iglesia tanto en su página web ("nuestra postura es de comunión con la Iglesia"5) cuanto en su página de Facebook ("somos miembros inalienables de la Iglesia Católica apostólica romana"6). Se trata, por lo tanto, de un caso de autonomización y publicitación de un "sujeto socio-eclesial" específico (el gay católico asumido), que manifiesta sus competencias comunicacionales en red.

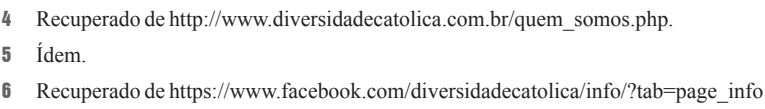


En una entrevista para esta investigación, Cristiana Serra, psicóloga miembro del grupo desde 2008, ofrece más detalles sobre el origen del grupo:

\begin{abstract}
El Diversidade nació en Internet. En 2006, un grupo de personas, algunas gays, otras no [...] todas muy ligadas al catolicismo, comenzaron a conversar sobre cómo conciliar estas dos identidades [gay y católica]. Y decidieron organizar un material, y así fue creada una página web. [...] Y es gracioso porque, a partir dela página web [...] comenzó a surgir la demanda, porquelas personas comenzaron a buscar en Internet, a llegar a la página web, a entrar en contacto. [...] Y las personas comenzaron a pedir ayuda, a sacarse dudas y a pedir orientación. Entonces, la demandapor encuentros presencialessurgió a partir del surgimiento de la página web [...]. Entonces, fue surgiendo una pequeña "redecita" allí, que creó la página web (Información personal, 16 octubre de 2015; trad. y cursivas nuestras).
\end{abstract}

De este modo, la conciliación de las dos identidades, católica y gay, por parte del grupo, está permeada por las posibilidades de la cultura socio-digital, mediante la creación de una página web, que favoreció una demanda en términos de ayuda, dudas, orientación, encuentros por parte de la sociedad en general. La "redecita" offline generó la red online, con mayor alcance. Aquello que subyacía de modo latente en el interior de la Iglesia Católica encontró un "punto de escape" comunicacional, una "grieta en el armario" eclesial, gracias a una acción simbólica en el ambiente digital.

Se trata, por lo tanto, de una "minoría periférica" emergente comunicacionalmente en el contexto eclesial contemporáneo. Pero su "minoridad" va más allá de la inferioridad cuantitativa de sus miembros (sea en términos digitales, con sus poco más de 4,5 mil "me gusta" en la página de Facebook, por ejemplo, sea en términos socio-eclesiales, en comparación con una "mayoría" católica) y comprende principalmente el hecho de luchar por tener una voz activa en el contexto eclesial, de "hacerse oír" por parte de la Iglesia Católica como un todo, ya que las personas gays, en el ámbito católico, todavía no tienen acceso a "voz plena" en las principales instancias de la vida de la institución eclesiástica. Las personas homosexuales, en el contexto católico, pueden ser vistas como minoría pues se constituyen como "un lugar donde se animan los flujos de transformación de una identidad [católica] o de una relación de poder [eclesial]", promoviendo "una toma de posición grupal en el interior de una dinámica conflictiva" en torno a las cuestiones de género (Sodré, 2005, p. 12, trad. nuestra).

Por proponer un discurso disidente (según ciertas lecturas sociales, y hasta herético, según ciertas lecturas católicas), el grupo se sitúa tanto en la frontera eclesial, como en la frontera social. Por eso, señala aquello que el propio Papa Francisco llama de "periferias existenciales". En el ámbito eclesial, las personas homosexuales, como es el caso de Diversidade Católica, no están en el "centro", pues, en la cultura católica en general, ellas todavía son vistas, a pesar de todo el avance dela reflexión eclesial, como "pecadoras", “anómalas", "patológicamente 
desviadas" (cf. Valle, 2014), distantes de un supuesto ideal cristiano. Como periferia, Diversidade Católica se inserta en el conjunto de "sistemas culturales que se caracterizan por estar menos regulados (menos descriptos) por parte de dos 'núcleos' dominantes de estos sistemas', como la institución eclesial (Ibrus, 2015, p. 236). Por eso, el grupo actúa de forma relativamente autónoma dentro de la Iglesia, como vanguardia o subcultura católica, con cierta independencia de las estructuraciones de poder eclesiales.

La amplitud y el alcance comunicacional del grupo, a pesar de su "minoridad periférica", lograron una catalización y una exponenciación con la creación de la página en Facebook. Según Cristiana:

Facebook con seguridad se tornó un enorme canal de contacto. Muy grande, muy grande. Son muchos mensajes por día. (...) Mucha gente, mucha gente llegó al grupo por Facebook (...). Dehecho, me arriesgaría a decir que Facebook hoy es nuestro principal canal de comunicación (Información verbal, 16 de octubre de 2015, trad. y cursivas nuestras).

Ese proceso comunicacional encontró su ápice en el proceso de divulgación, realización y evaluación del $1^{\circ}$ Encuentro Nacional de Católicos LGBT, celebrado en Río de Janeiro el 26 de julio de 2014, reuniendo decenas de participantes. El encuentro fue promovido y divulgado por el grupo Diversidade Católica, junto a otros diversos grupos católicos gays de Brasil, para ser un momento de compartir e intercambiar experiencias entre católicos LGBTs brasileños sobre "quiénes son, cómo viven su identidad religiosa, cómo sienten la comunidad de la cual forman parte y cómo se da su actuación a través de varios grupos de laicos organizados"7. Según Cristiana Serra:

Mucha gente llegó al encuentro [nacional] por Internet, por la página del evento en Facebook. Como plataforma, es impresionante el nivel de interacción [en Facebook]. Y la cuestión de la interactividad, en el mejor sentido posible, de estas formaciones, de estas interacciones y formaciones sociales espontáneas, que suceden, es una cosa rizomática en esa plataforma. Como fenómeno, es muy interesante, muy rico y toma cuerpo. El Encuentro Nacional, sin Facebook [...], no hubiera sucedido (Información verbal, 16 de octubre de 2015, trad. y cursivas nuestras).

Se percibe ahí, por lo tanto, la relevancia de la construcción de redes comunicacionales online, que permiten que algo inédito (como un evento católico gay público) sea posible gracias a las interacciones socio-digitales. Como resultado del Encuentro Nacional, fue publicado un manifiesto acerca de los principios que orientan la acción y la contribución de los grupos en torno a la ciudadanía LGBT en la Iglesia. Por otro lado, también fue articulada una Red Nacional de Grupos Católicos LGBT, congregando varios grupos

7 Recuperado de https://goo.gl/gLB3Nf. 
de católicos LGBT brasileños. Esa red, luego de su articulación, asumió como "sede", precisamente, una página oficial en Facebook ${ }^{\mathbf{8}}$.

El Encuentro Nacional y la tensión social y eclesial que provocó ${ }^{9}$ señalan el proceso de circulación de lo "católico" en red, involucrando innumerables interrelaciones entre el grupo y los demás inter-agentes: una red offline de personas y grupos católicos gays que activan redes comunicacionales online en Facebook en torno del evento que, como principal resultado, da origen ala "institucionalización" de una red nacional de católicos gays con sede en Facebook.

La página Diversidade Católica en Facebook, en suma, apunta a procesos de transformación del catolicismo en el caldo cultural contemporáneo ydemanda, para su observación, un desvío y un desplazamiento de la mirada, para percibir la circulación de lo "católico" y la propia construcción del catolicismo también a partir de acciones comunicacionales alternativas, periféricas, minoritarias y no solamente desde el punto de vista central de la institución eclesiástica sobre la cuestión homosexual. O sea, en el ámbito de la mediatización digital del catolicismo, la página Diversidade Católica es un "dispositivo simbólico, con una intencionalidad ético-política dentro de la lucha contra-hegemónica" (Sodré, 2005, p. 12) en el universo católico. Por lo tanto, la mediatización digital de la religión explicita justamente las acciones "microbianas" de estos agentes, que no son históricamente nuevas dentro del espectro del catolicismo, sino que emergen socialmente gracias a Internet.

Ampliando el análisis, en este sentido, lo "religioso" sería la manifestación inferencial de que la existencia social de las religiones hoy, especialmente en el ambiente digital, es todavía más fuertemente el resultado de la interacción comunicacional. Se entrevé, en la multiplicidad y en la imprevisibilidad de los inter-agentes y de sus interacciones en red sobre lo "religioso", la construcción yla reconstrucción de un universo simbólico estable, pero no estático ni monolítico, a partir de la diversidad religiosa. Con el surgimiento de un acceso y una enunciación públicos sobrelas religiones por parte de la sociedad, los sujetos se cubren de un poder de producción simbólica antes detentado solamente por las instituciones religiosas o mediático-corporativas. La articulación entre prácticas comunicacionales sobre la religión y plataformas tecnológicas de acceso público y alcance ubicuo desencadena un proceso de liberación de una gran energía social de reconstrucción cultural de los sentidos religiosos.

Históricamente, las instituciones religiosas poseían el control de su "mensaje" y de los medios para su transmisión como intermediaria entre la producción del saber y su difusión en la sociedad -bajo pena, en el caso católico, de ser considerado hereje, ser listado en el Index, o hasta ser quemado en la hoguera. El ejercicio de la censura y la represión estuvo presente en un periodo extenso

8 Recuperado de https://www.facebook.com/redenacionalcatolicoslgbt.

9 Eleventorepercutió mediáticamente, por ejemplo, en algunos de los principales diarios brasileños, como OEstado deS.Paulo (http://goo.gl/eZq4jW), O Globo (http://goo.gl/dJUInM) y OPovo (http://goo.gl/CxpaFe), entre otros. 
e intenso de la historia mediante la institución de la Inquisición: el mensaje cierto, vehiculizado por las personas ciertas en el medio cierto, garantizaría la fijación de las creencias y de la tradición religiosas

Hoy, sin embargo, el ambiente online ofrece innumerables alternativas de presencia, debate y acción religiosos públicos para individuos y grupos que tradicionalmente quedarían al margen (o hasta fuera) de las instituciones religiosas, principalmente las cristianas, pero que a partir de la evolución social, luchan comunicacionalmente por su ciudadanía religiosa, como por ejemplo los homosexuales. Con el avance de la mediatización digital de la religión, lo "religioso" explota en una multiplicidad de significaciones locales sobre lo sagrado, muchas veces minoritarias y subculturales, mediante agentes sociales que toman la palabra públicamente, apuntando a la contingencia, la relatividad y la limitación de todo y cualquier sistema de valor religioso.

Así como Copérnico, al remover la Tierra del centro del universo, reveló una concepción totalmente nueva que se tornó una visión del mundo, sacudiendo fuertemente las estructuras y los paradigmas institucionales de la Iglesia, así también las actuales prácticas religiosas en redes comunicacionales online revelan una concepción del mundo religioso en que, aunque haya una institución religiosa bien delimitada por sus leyes y protocolos internos, como en el caso católico, cada vez más los individuos, alejándose de ese "centro", se apropian de lo "religioso" y lo reconstruyen públicamente, trasladando y desviando la "centralidad" de la identidad propia de la Iglesia, que, al "encarnarse" en red, se ve desprovista de un punto central.

Algunas construcciones sobre lo "religioso" se propagan de "arriba para abajo", a partir de las instituciones, siendo después apropiadas por una serie de públicos diferentes, circulando por la cultura. Otros emergen de "abajo para arriba", a partir de varios agentes sociales, e impregnan la cultura socio-digital predominante. Se ve que el poder de las redes comunicacionales online es que ellas diversifican y amplifican al mismo tiempo. La construcción social en red genera una mayor diversidad cultural sobre las religiones, y el refuerzo público de las institucionalidades religiosas intenta garantizar la no fragmentación cultural de sus doctrinas y tradiciones. Pero ambas reescriben, modifican, corrigen, expanden lo "religioso", mediante la puesta en circulación.

En la tensión comunicacional entre la acción institucional religiosa (marcada por el foco en la permanencia) y la acción social de los sujetos conectados (marcada por la búsqueda de cambio), se opera una dialéctica que incide sobre la estructura tradicional de las religiones, demarcando un movimiento histórico de permanencia-cambio. Por eso, parece no ser más posible definir de antemano lo que es "legítimo" o "auténtico" en las religiosidades digitales. Lo que la mediatización digital permite constatar es el surgimiento de nuevas modalidades de construcción de la identidad religiosa mediante relaciones e interacciones emergentes que constituyen nuevas modalidades de comunidad. 
En éstas, se experimentan nuevas modalidades de ritualidad, en que prácticas religiosas tradicionales son digitalizadas, y nuevas formas de contacto con las realidades sagradas van surgiendo en red. La autoridad religiosa, como el Papa, también se seculariza en el contacto entre diversas alteridades religiosas en conexión (vía Twitter o Instagram), que trasladan aquella autoridad a otras modalidades emergentes.

Ya no es sólo la heteronomía institucional religiosa que determina y define el discurso y la práctica religiosa, sino también la autonomía de las personas en conexión que permite la innovación y la invención de lo "religioso" a partir de acciones y prácticas comunicacionales en red. Por lo tanto, las prácticas sociales de construcción de sentido, en sociedades en mediatización, revelan que los puntos-clave de las religiones y de las expresiones religiosas -como identidad, comunidad, autoridad, ritualidad- se constituyen comunicacionalmente, en interacciones locales, mediante lógicas mediáticas.

\section{CONCLUSIÓN}

Con el avance de la mediatización, los media y las religiones -dos grandes sistemas sociales simbólicos- pasan a encontrar nuevos desdoblamientos. Siendo medios de expresión social, los media y las religiones, al existir en un ambiente social marcado por nuevos procesos mediáticos, pasan a hacer un "trabajo" cultural diferente del que venían haciendo históricamente. Podemos decir que la propia ruptura de una distinción clara y evidente entre "media" y "religión" sería, justamente, uno de los efectos de la mediatización.

Más allá de las especificidades religiosas de cada tradición, la mediatización digital pluraliza la propia noción de religión, mediante una mayor reflexividady flexibilidad de las más diversas religiosidades y expresiones religiosas. En redes comunicacionales online, el fenómeno religioso se manifiesta no sólo como acciones de religación (religare) entre lo humano y lo divino, pero principalmente de reconexión entre lo humano, lo social, lo tecnológico, lo simbólico, lo divino: la reconexión comunicacional en red pasa a complejizar el papel de la religión, en el sentido de conectar simbólicamente aquello que no se conectaba históricamente en cada tradición religiosa; de conectar simbólicamente, mediante prácticas sociocomunicacionales de los sujetos en red, aquello que, en la realidad, está (o, segúnlas instituciones religiosas, debería estar) desconectado, separado.

Vemos ahí lógicas comunes, modus operandi semejantes, en que media y religiones actúan como medios de percepción, organización y expresión deinstancias diferentes de la experiencia humana (lo privado y lo público, lo sagrado y lo profano, lo arcaico y lo moderno, lo tradicional y lo contemporáneo). En estas interrelaciones, lo mediático no es accesorio ni indispensable, y lo religioso tampoco es mero epifenómeno: ambos se articulan en una circularidad auto-productiva. Religiones y media son productos y productoras de su propia 
interfaz:las religiones son como son porquela sociedad asítambién las significa mediáticamente; ylos media son como son porquelas religiones asítambién los significan socialmente. Tal interfaz es compleja y se manifiesta en formas cada vez más flexibles, de poli-sistemas mediático-religiosos emergentes.

O sea, la lógica mediática no se sobrepondría a la religiosa, o viceversa: de este encuentro, surgirían-mediante ajustes, conflictos, negociaciones-lógicas conjuntas y plurales entre los media y las religiones, que no son específicamente "propiedad" de ninguno de los polos. Se trata de una interfaz multiforme, que, no siendo definida exclusivamente ni por la religión ni por los media, da origen a un "medio" múltiple y mutante, a inter-lógicas mediático-religiosas híbridas, que traspasan tanto los media como las religiones. La mediatización de la religión, de esta forma, es un fenómeno-tercero que surge en el intersticio comunicacional entre procesos mediáticos y procesos religiosos.

Por eso no estaríamos simplemente delante de un periodo entre la extinción de un modelo "oficial" de religión y el surgimiento de un nuevo modelo "oficial", sino que estaríamos delante del "nacimiento de una nueva forma social de religión" (Luckmann, 2014, p. 124; trad. y cursivas nuestras), con el surgimiento de nuevasformas de percepción, experiencia, yexpresión contemporáneas delo "religioso"-marcadamentemediatizadas-.Entre reconstruccionesy resistencias, lo "religioso" fluye en nuevos contextos de significación social. Sus desdoblamientos quedan como cuestiones abiertas, a ser profundizadas por estudios futuros.

\section{REFERENCIAS}

Alves, R. C. (2013, 31 de julio ). Passamos dos meios de massa para a massa de meios. En Valor Econômico. Recuperado de http://goo.gl/Mtajae

Benedicto XVI (2009). Nuevas tecnologías, nuevas relaciones. Promover una cultura de respeto, de diálogo, de amistad (Mensaje para la 43 Jornada Mundial de las Comunicaciones Sociales). En Vatican.va. Recuperado de http://goo.gl/OhZUka

Benedicto XVI (2013). Redes Sociales: portales de verdad y de fe; nuevos espacios para la evangelización (Mensaje para la $47^{\circ}$ Jornada Mundial de las Comunicaciones Sociales). En Vatican.va. Recuperado de http://goo.gl/C3lCMV

Braga, J. L. (2012). Circuitos versus Campos Sociais. En M. Â. Mattos, J. Janotti Junior \& N. Jacks (orgs.), Mediação e Midiatização (pp. 31-52). Salvador, Brasil: EDUFBA.

Burity, J. A. (2003, diciembre). Mídia e religião: regimes do real entre o mistério, o aparente e o virtual. En Religião \& Sociedade, 23 (2), pp. 77-91. 
Couldry, N. (2010, julio-diciembre,). A mídia tem futuro? En MATRIZes, 4(1), pp.51-64. Recuperado de http://goo.gl/0NPKaq

Friesen, N.yHug, T. (2009). The Mediatic Turn: Exploring Concepts for Media Pedagogy. En K. Lundby (org.). Mediatization: Concept, Changes, Consequences (pp. 63-84). New Yorke: Peter Lang Publishing.

Gomes, P. G. (2008). O processo de midiatização da sociedade e sua incidência em determinadas práticas sociossimbólicas na contemporaneidade: a relação mídia e religião. En A. Fausto Neto et al. (eds.). Midiatização e processos sociais na América Latina (pp.17-30). São Paulo : Paulus.

Gomes, P.G.(2010).DaIgrejaEletrônicaà Sociedadeem Midiatização.São Paulo:Paulinas.

Gomes, P. G. (2012). O caleidoscópio midiático. En P. Gomes et al. (eds.). Mídias e religiões: a comunicação e a fé em sociedades em midiatização (pp. 18-20). São Leopoldo, Brasil: Ed. Unisinos-Casa Leiria.

Gomes, P.G. (2013). Como o processo de midiatização (um novo modo de ser no mundo) afeta as relações sociais? En J. L. Braga et al. (eds.). Dez perguntas para a produção de conhecimento em comunicação (pp. 127-139). São Leopoldo, Brasil: Unisinos.

Gomes, P. G. (2015). Midiatização: um conceito, múltiplas vozes. En A. Fausto Neto et.al. (eds.). Relatos de investigaciones sobre mediatizaciones (p. 33-54). Rosario, Argentina: UNR Editora.

Gutiérrez, L. I. S. (2010). Posfácio. Religiosidade hipermidiatizada. En V. Borelli (ed.). Mídia e religião: entre o mundo da fé e o do fiel (pp.189-194). Rio de Janeiro: E-papers.

Hepp, A. (2012). Cultures of Mediatization. Cambridge, UK: Polity.

Hjarvard, S. (2013). The Mediatization of Culture and Society. New York: Routledge.

Hoover, S. M. (2006). Religion in the Media Age. New York: Routledge.

Hoover, S. M. (2009). Complexities: The Case of Religious Cultures. En K. Lundby (ed.). Mediatization: Concept, Changes, Consequences (pp. 123-138). New York: Peter Lang Publishing.

Hoover, S. M. (2014). Media, Culture, and the Imagination of Religion. En C. Christians $\&$ K. Nordenstreng (eds.). Communication Theories in a Multicultural World (pp. 197-212). New York: Peter Lang.

Horsfield, P. (2015). From Jesus to the Internet: A History of Christianity and Media. West Sussex, England: Wiley Blackwell.

Ibrus, I. (2015). Una alternativa: la evolución de los medios abordada desde la semiótica de la cultura. En C. A. Scolari. Ecología de los medios: entornos, evoluciones e interpretaciones (pp. 221-246). Barcelona: Gedisa. 
Knoblauch, H. (2014). A dissolução da religião no religioso. En T. Luckmann. A religião invisível (pp. 4-33). São Paulo: Olho D’Água-Loyola.

Krotz,F. (2007). The Meta-Process of 'Mediatization' as a Conceptual Frame. En Global MediaandCommunication,3,pp.256-260. Recuperadodehttp://migre.me/4Cvan

Lima, L. C. (2014, julio-agosto). Homoafetividade e evangelização: abrir caminhos. En Vida Pastoral, 55 (297), pp. 29-36. Recuperado de http://goo.gl/zLV7ro.

Luckmann, T. (2014). A religião invisível. São Paulo, Brasil: Olho D’Água-Loyola.

Martelli, S. (1995). A religião na sociedade pós-moderna: entre secularização e dessecularização. São Paulol: Paulinas.

Martino, L. M. S. (2012). Mediação e midiatização da religião em suas articulações teóricas e práticas: um levantamento de hipóteses e problemáticas. En M. Â. Mattos, J. Janotti Junior e N. Jacks (orgs.), Mediação e Midiatização (pp. 219-244). Salvador, Brasil: EDUFBA.

Martino, L. M.S. (2015, julio-diciembre). A mediatização do campo religioso: esboço de uma síntese possível. En Comunicação \& Informação, 18 (2), pp.6-21. Recuperado de http://goo.gl/ZxJo4x

Miklos, J. (2012). A ciber-religião: a midiatização do sagrado e a sacralização da mídia. En P. Gomes et al. (eds.). Mídias e religiões: a comunicação e a fé em sociedades em midiatização (pp.181-193). São Leopoldo, Brasil: Ed. Unisinos-Casa Leiria.

Pace, E. (2013). La comunicazione invisibile: le religioni in internet. Milano: San Paolo.

Pondé, L. F. (2011). O catolicismo hoje. São Paulo: Benvirá.

Sbardelotto, M. (2012). E o Verbo se fez bit: a comunicação e a experiência religiosas na internet. Aparecida, Brasil: Santuário.

Sbardelotto, M. (2013). O caso @Pontifex e a reconstrução do religioso em dispositivos conexiais. En Logos, 2, pp. 57-72. Recuperado de http://goo.gl/uXIkt4

Sbardelotto, M. (2014). La reconstrucción de lo "religioso" en la circulación en redes socio-digitales. En La Trama de la Comunicación, 18, pp. 151-170. Recuperado de http://goo.gl/QqaVTw

Sbardelotto, M. (2016a, 4 de abril). @Franciscus, o papa no Instagram. Uma breve análise comunicacional. En IHU On-Line, 1, pp. 17-19. Recuperado de http:// goo.gl/OG4fle

Sbardelotto, M. (2016b). Eo Verbo se fez rede: uma análise da circulação do "católico" em redes comunicacionais online. (Tesis de doctorado). Universidade do Vale do Rio dos Sinos, São Leopoldo, Brasil. Recuperado de https://goo.gl/QZ4kNm

Sodré, M. (2005). Por um conceito de minoria. En R. Paiva e A. Barbalho (eds.). Comunicação e cultura das minorias (pp. 11-14). São Paulo: Paulus. 
Sodré, M. (2012). Antropológica do espelho. Petrópolis, Brasil: Vozes.

Sodré, M. (2014). A ciência do comum: notas para o método comunicacional. Petrópolis, Brasil: Vozes.

Sousa, T. M. (2011, 12 de septiembre). A Igreja na internet: surgimento de uma religião 2.0. En IHU On-Line, 373, pp. 27-28.

Teixeira, F. \& Menezes, R. (2009). Catolicismo plural: uma introdução. En F. Teixeira y R. Menezes (eds.). Catolicismo plural: dinâmicas contemporâneas (pp. 7-14). Petrópolis, Brasil: Vozes.

Valle, E. (2014, julio-agosto). A Igreja Católica ante a homossexualidade: contextualizações e indicações pastorais. En Vida Pastoral, 55 (297), pp. 9-28. Recuperado de http://goo.gl/zLV7ro.

Verón, E. (2012). Prólogo: La mediatización, ayer y hoy. En M. Carlón \& A. Fausto Neto (eds). Las políticas de los internautas: nuevas formas de participación (pp. 9-16). Buenos Aires: La Crujía.

Verón, E. (2014, enero-junio). Teoria da midiatização: uma perspectiva semioantropológica e algumas de suas consequências. En MATRIZes, 1, pp. 13 19. Recuperado de http://goo.gl/OauFDM

\section{IDENTIFICACIÓN DEL AUTOR:}

Moisés Sbardelotto es Doctor y Máster en Ciencias de la Comunicación por laUniversidade do Vale do Rio dos Sinos (UNISINOS), Brasil, con intercambio doctoral en la Università di Roma "La Sapienza", Itália. Además es Graduado en Comunicación Social-Periodismo por la Universidade Federal do Rio Grande do Sul (UFRGS), Brasil. Es colaborador del Instituto Humanitas Unisinos (IHU) y fue miembro delaComisión Especial para elDirectorio deComunicación parala Iglesia en Brasil, Conferencia Nacional de los Obispos de Brasil (CNBB). De 2008 a 2012 coordinó la oficina brasileña de la Fundación Ética Mundial(Stiftung Weltethos). Es autor de Eo Verbo sefezrede: religiosidades em reconstrução no ambiente digital (en prensa) y de Eo Verbo se fez bit: a comunicação e a experiência religiosas na internet (2012).

\section{REGISTRO BIBLIOGRAFICO:}

Sbardelotto, M. (2016, diciembre). Mediatización de la religión: La relación entre lo 'religioso' y lo mediático en tiempos de red. En InMediaciones de la Comunicación, 11, pp. 113-137. Revista de la Escuela deComunicación, Facultad de Comunicación y Diseño, Universidad ORT Uruguay, República Oriental del Uruguay. 